\title{
REVIEW
}

\section{Facial pain: sinus or not?}

\section{Algie cranio facciali: dolore di origine sinusale?}

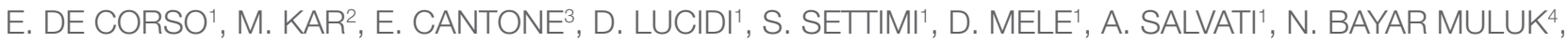 \\ G. PALUDETTI ${ }^{1}$, C. CINGI ${ }^{5}$ \\ ${ }^{1}$ Fondazione Policlinico Universitario A. Gemelli IRCCS, Università Cattolica del Sacro Cuore, Rome, Italy; ${ }^{2}$ ENT \\ Specialist Kumluca State Hospital, ENT Clinic, Antalya, Turkey; ${ }^{3}$ Department of Neuroscience, ENT section, "Federico \\ II" University, Naples, Italy; ${ }^{4}$ Kirikkale University, Medical Faculty, Department of Otorhinolaryngology,Kirikkale, Turkey; \\ ${ }^{5}$ Eskisehir Osmangazi University, Medical Faculty, Department of Otorhinolaryngology, Eskisehir, Turkey
}

\section{SUMMARY}

Facial pain remains a diagnostic and therapeutic challenge for both clinicians and patients. In clinical practice, patients suffering from facial pain generally undergo multiple repeated consultations with different specialists and receive various treatments, including surgery. Many patients, as well as their primary care physicians, mistakenly attribute their pain as being due to rhinosinusitis when this is not the case. It is important to exclude non-sinus-related causes of facial pain before considering sinus surgery to avoid inappropriate treatment. Unfortunately, a significant proportion of patients have persistent facial pain after endoscopic sinus surgery (ESS) due to erroneous considerations on aetiology of facial pain by physicians. It should be taken into account that neurological and sinus diseases may share overlapping symptoms, but they frequently co-exist as comorbidities. The aim of this review was to clarify the diagnostic criteria of facial pain in order to improve discrimination between sinogenic and non-sinogenic facial pain and provide some clinical and diagnostic criteria that may help clinicians in addressing differential diagnosis.

KEY WORDS: Facial pain $\bullet$ Headache $\bullet$ Migraine $\bullet$ Cranial neuralgia $\bullet$ Rhinogenic $\bullet$ Non-rhinogenic

\section{RIASSUNTO}

Le algie cranio-facciali rappresentano una sfida sia dal punto di vista diagnostico che terapeutico. Nella pratica clinica, è frequente che $i$ pazienti affetti da tale condizione si sottopongano a più valutazioni da parte di specialisti diversi, ricevendo trattamenti medici e chirurgici eterogenei e inappropriati, che non portano al beneficio clinico. Questo purtroppo accade perché la sintomatologia algica cranio facciale viene spesso attribuita erroneamente alla rinosinusite. $\grave{E}$ importante, invece, escludere le cause di dolore facciale di origine diversa dall'eziologia nasosinusale, prima di prendere in considerare l'eventualità di un trattamento chirurgico che potrebbe rivelarsi inutile e inappropriato. Per tali motivi sfortunatamente, una significativa percentuale di pazienti trattati chirurgicamente per le algie cranio facciali continua a lamentare dolore persistente anche dopo la chirurgia endoscopica nasosinusale. È necessario tenere in considerazione che le patologie neurologiche possono presentare sintomi sovrapponibili a quelli delle patologie nasosinusali e che le due entità possono in alcuni casi coesistere come comorbidità. L'obiettivo del seguente lavoro è quello di chiarire i criteri diagnostici delle algie cranio-facciali allo scopo di migliorare la diagnosi differenziale tra dolore dovuto a patologie nasosinusali e quello dovuto ad altre cause, fornendo al contempo criteri clinici che possano essere d'aiuto ai curanti, indirizzandoli verso la corretta diagnosi e l'appropriato iter terapeutico.

PAROLE CHIAVE: Algia cranio facciale $\bullet$ Cefalea $\bullet$ Emicrania $\bullet$ Nevralgia cranica $\bullet$ Rinogeno $\bullet$ Non rinogeno

Cite this article as: Acta Otorhinolaryngol Ital 2018;38:485-496. https://doi.org/10.14639/0392-100X-1721

(C) Società Italiana di Otorinolaringoiatria e Chirurgia Cervico-Facciale

\section{Introduction}

Facial pain is associated with significant morbidity and high levels of health care utilisation, and remains a diagnostic and therapeutic challenge for both clinicians and patients; these conditions are often regarded as diagnoses of exclusion. The diagnostic criteria for facial pain can be found in both the International Association for the Study of Pain classification (IASP) and the International Head- ache Classification (ICHD-III) ${ }^{1}$. According to the IASP, pain is an unpleasant emotional and sensory experience associated or not with real or potential injury; neuropathic pain occurs due to neural dysfunction ${ }^{23}$. In the group of patients who are referred to an otolaryngologist with a presumptive diagnosis of rhinosinusitis as the cause of facial pain, only a few cases are found to have pain attributable to sinus diseases ${ }^{4}$. Furthermore, studies selecting pa- 
tients with facial pain with negative nasal endoscopy (NE) and computed tomography (CT) found that migraine was the most common cause of pain. Finally, clinical observations suggest that rhinosinusitis is an uncommon cause of facial pain:

- more than $80 \%$ of patients with purulent secretions visible at nasal endoscopy have no facial pain ${ }^{4}$;

- most patients with nasal polyposis do not have facial pain ${ }^{56}$;

- children who have rhinosinusitis rarely complain facial pain, even in the presence of florid purulent secretions ${ }^{7}$;

- a significant proportion of patients who are candidate for endoscopic sinus surgery for facial pain have symptoms that persist post-operatively ${ }^{489}$.

The management of patients with sinus pressure, pain, fullness, or headache is of utmost importance in the field of otolaryngology and rather challenging. From a merely clinical point of view, it is crucial distinguishing "sinogenic" from "non-sinogenic" facial pain to avoid erroneous treatment. Migraines are commonly misdiagnosed as sinus headache in approximately $42 \%$ of patients ${ }^{10}$ due to sharing overlapping symptoms (facial pain-fullness, nasal congestion and rhinorrhoea), precipitating triggers (weather changes, allergies and environmental irritants) and common locations with chronic rhinosinusitis (CRS) ${ }^{11}$. Furthermore, sinonasal and migrainous disorders may frequently co-exist as comorbidities; in fact, chronic rhinosinusitis (CRS) may increase migraine-associated morbidity and frequency through irritation of trigeminal nerve receptors. Although American Academy of Otolaryngology-Head \& Neck Surgery (AAO-HNS) criteria mandate objective confirmation by either NE or CT, non-otolaryngologists do not usually perform nasal endoscopy and the use of CT scan is limited due to radiation exposure and costs.

The aim of this work was to clarify the diagnostic criteria of sinogenic facial pain and to study differential diagnosis between sinogenic and non-sinogenic facial pain, as well as diagnostic-related strategies in patients presenting to an otolaryngologist for facial pain or headache ${ }^{12}$.

\section{Epidemiological data}

Several epidemiological reports have been published regarding the relationship between sinus inflammatory disorders and headache, reaching different results. The clinical picture may be confounding due to overlapping symptoms. Runny nose, congestion and ocular symptoms may also be associated with neurological conditions. Migraine patients, for example, feel significantly bothered by nasal symptoms: a study on 46 patients diagnosed with primary headache disorder (PHD) showed high sino-nasal outcome test (SNOT-22) scores in almost all patients in whom CRS had been excluded by objective criteria ${ }^{12}$. Accordingly, Barbanti et al. ${ }^{13}$ demonstrated that migraine patients may experience unilateral nasal and/or ocular symptoms. Ocular and nasal symptoms have been hypothesised to arise from activation of the trigeminal-autonomic reflex, which is mediated by a circuit of trigeminal afferents and parasympathetic efferents innervating the lacrimal glands and the nasal mucosa.

Several authors have demonstrated that the most common cause of self-diagnosed or primary physician-diagnosed "sinus headaches" in primary care scenarios is migraine. Schreiber et al. ${ }^{14}$ observed, in a very large series of 3000 patients with a self-diagnosis of "sinus headache", that $88 \%$ of cases had migraine. Accordingly Eross et al. ${ }^{15}$ demonstrated that $86 \%$ of patients with a self-diagnosis and/or physician diagnosis of "sinus headache" have a migraine; Mehle et al. ${ }^{16}$ observed, finally, in a cohort of 35 patients affected by self-referred "sinus headache" that $74.3 \%$ satisfied International Headaches Society (IHS) criteria for migraine.

Several studies selecting otorhinolaryngological patients with negative NE and CT also found migraine to be the most common cause of sinus headaches. Perry et al. ${ }^{17}$, for instance, observed that $58 \%$ of patients referring for self-diagnosed "sinus headache" in a tertiary rhinology practice, with negative NE or CT, were more properly diagnosed as migraine after referral to a neurologist.

Conversely, in studies from non-otorhinolaryngological settings, migraine is frequently misdiagnosed as sinusitis ${ }^{18}$. Lee ${ }^{19}$ observed that $28.7 \%$ of 1,235 patients diagnosed with primary headache and treated by neurologists in the emergency room showed radiological signs of rhinosinusitis, intranasal contact point, septal spur, concha bullosa, isolated sphenoid lesion or osteoma.

Several epidemiological studies have confirmed that CRS and migraine may also be frequently comorbid, due to the high incidence of both disorders in the general population. Aaseth ${ }^{20}$ showed a strong association between headache and CRS in a cohort of 30,000 individuals, aged 3044 years: patients with CRS had a 9-fold increased risk of having chronic headache; rhinitis and CRS are also believed to increase migraine-associated morbidity. Moreover, a study conducted on 100 headache patients demonstrated that $54 \%$ of those with IHS-defined migraine reported allergic rhinitis and $76 \%$ had at least one episode of prior acute sinusitis ${ }^{15}$.

\section{"Sinogenic" facial pain}

The term "sinogenic" facial pain is routinely used to 
suggest a pathogenic relationship between rhinological disorders and facial pain, and several physiopathological theories have been postulated ${ }^{21}$. A "convergence hypothesis" has been elaborated, suggesting that headache might be a rebound mechanism that occurs when the central nervous system is stimulated by a headacheprovoking environmental trigger. Sinus headache may be the result of trigeminal afferents in the nasal and sinus territory that activate the trigemino-vascular system. Peripheral trigger would occur with immunologic activation from allergies or infection or from stimulation derived from abnormal anatomic features culminating in facial pain ${ }^{11}$. In addition, the creation of a pressure differential across obstructed sinus ostia, presence of inflammation and bacterial toxins and underlying osteitis may influence sensory nerve function and contribute to the aetiology of headache.

\section{Rhinosinusitis and facial pain}

Acute rhinosinusitis (ARS) usually follows an acute upper respiratory tract infection. Pain related to ARS is often unilateral, severe and associated with fever in $50 \%$ of cases and with nasal obstruction. Unilateral facial and dental pain are predictors of maxillary infection as validated in studies using maxillary sinus aspiration ${ }^{22}$. Acute frontal ARS is often characterised by pyrexia and tenderness on the medial side of the orbital floor under the supraorbital ridge, where the frontal sinus is thinnest. Endoscopic examination is mandatory and usually shows hyperemia of the sinonasal mucosa, and purulent secretions. Acute sphenoiditis is uncommon, causing pain at the vertex of the head, although pain can be referred to the temporal region or the whole head.
In the CRS there is a poor correlation between the site of facial pain and evidence of sinus pathology. Indeed, CRS is usually painless, although the pain may occur during acute exacerbations. The relationship between facial pain/ pressure, headache and chronic rhinosinusitis has long been debated and the most recent guidelines endorse the presence of pain in CRS ${ }^{23}$. Several studies, however, suggested that facial pain is a very rare symptom in CRS ${ }^{24}$. Hirsch et al. ${ }^{25}$ suggested that only $9.1 \%$ of patients affected by CRS refer facial pressure/pain as prevalent symptoms. CRS patients most commonly have other clinical manifestations of rhinosinusitis, such as purulent nasal discharge and respiratory obstruction ${ }^{14} 26$, with pain occurring usually, as mentioned above, only during an acute exacerbation ${ }^{9}$. Furthermore, more than $80 \%$ of patients with purulent secretions visible at nasal endoscopy have no facial pain ${ }^{4}$.

CRS patients with facial pain and/or pressure have a higher risk of migraine compared to the patients without these symptoms. CRS may increase migraine-associated morbidity and migraine frequency through irritation of trigeminal nerve receptors. Additionally, the age- and sexspecific prevalence of CRS with pain and pressure mirror those of migraine (middle age, women) ${ }^{20}$.

Diagnostic criteria for headache attributed to rhinosinusitis are listed in Table I.

\section{Rhinogenic headache}

There has been a growing level of interest shown in rhinogenic headache $(\mathrm{RH})$ within the literature over the last two decades. Despite this, the sum of knowledge on RH remains low. Whilst the IHS does accept such a condition, the society has remarked on the paucity of evidence for $\mathrm{RH}$ as

Table I. Diagnostic criteria for headache attributed to rhinosinusitis. Headache Classification Committee of the International Headache Society (IHS) ${ }^{1}$.

\section{Attributed to acute rhinosinusitis}

A. Any headache fulfilling criterion $C$

B. Clinical, nasal endoscopic, and/or imaging evidence of acute rhinosinusitis

C. Evidence of causation demonstrated by at least 2 of the following: 1. headache as developed in temporal relation to the onset of rhinosinusitis;

2. either or both of the following:

a. headache as significantly worsened in parallel with worsening of the rhinosinusitis,

b. headache as significantly improved or resolved in parallel with improvement in or resolution of the rhinosinusitis;

3. headache is exacerbated by pressure applied over the paranasal sinuses;

4. in the case of unilateral rhinosinusitis, headache is localised and ipsilateral to it.

D. Not better accounted for/by another ICHD-III diagnosis

\section{Attributed to chronic or recurring rhinosinusitis}

A. Any headache fulfilling criterion $C$

B. Clinical, nasal endoscopic, and/or imaging evidence of current or past infection or other inflammatory process within the paranasal sinuses

C. Evidence of causation demonstrated by at least 2 of the following:

1. headache as developed in temporal relation to the onset of chronic rhinosinusitis;

2. headache waxes and wanes in parallel with the degree of sinus congestion and other symptoms of the chronic rhinosinusitis;

3. headache is exacerbated by pressure applied over the paranasal sinuses;

4. in the case of unilateral rhinosinusitis, headache is localised and ipsilateral to it.

D. Not better accounted for/by another ICHD-III diagnosis 
a nosological entity. RH is defined as a headache, or a pain syndrome affecting the face, caused by mucosal surfaces impinging on each other within the nose and sinuses and lacking evidence of inflammation, hyperplasia of mucosal surfaces, pus-filled discharge, polyposis within the nose or sinuses, or existence of a mass ${ }^{27}$. Normally, symptoms affect the area surrounding the orbit, the canthus medially and superiorly, or the zygomatic-temporal region and are one-sided, even if both sides may be affected in some cases. There is frequent recurrence of pain, the duration of which may be hours, interspersed with pain-free intervals. Where the mucosae impinge on each other, a "trigger point" may occur, with a resulting paroxysm of pain in the face area. Variations in anatomy can lead to impingement of structures on the nasal epithelium, the most frequently seen being a pneumatised middle turbinate (alternatively termed concha bullosa), which is a consequence of the way the ethmoidal sinus cells develop. Likewise, the middle turbinate may impinge painfully on the septum of the nose or the lateral wall, a situation Morgenstein ${ }^{28}$ called "middle turbinate headache syndrome". Excising a portion of the middle turbinate in this group has an apparent benefit in relieving headache ${ }^{29}$. On the balance of probability, as assessed through reviewing published case histories ${ }^{9}$, most such patients with aberrant anatomy obtain only partial relief or of short duration by surgery. Greenfield ${ }^{30}$ has proposed the theory that cutaneous branches of the nasal afferents of cranial nerve $\mathrm{V}$ synapse in the cerebral cortex, thus accounting for the perception of nasal stimulation as pain. Since the cortex is unable to localise these afferent impulses, they are perceived as referred facial pain ${ }^{31}$. Stammberger and Wolf ${ }^{32}$ suggest that anatomical aberrations may cause mucous pooling, with infection occurring with resultant facial pain. They hypothesise that impingement of mucosae may trigger discharge of the neurotransmitter peptide substance $P$, which is known to have a role in pain transmission, but do not offer further experimental corroboration of their theory.

To hypothesise a rhinogenic headache, three features must be present: an area of mucosal impingement, confirmed endoscopically or radiologically; infiltrating the suspicious area with local anaesthesia should abolish nociception for 5 minutes; the pain should disappear within a week ${ }^{1}$. In contrast, a recent publication observed that most individuals with an area of impingement do not perceive pain nor, where there is pain, does obliteration of the contact point usually cause facial pain to disappear completely ${ }^{33}$. Additionally, points of mucosal contact were discovered to occur with identical frequency in both symptomatic and asymptomatic individuals. Even more revealing, where individuals had one-sided pain that could be linked to a mucosal impingement, such lesions were also present asymptomatically in $50 \%$ of cases ${ }^{34}$.

\section{Impact of functional endoscopic sinus surgery (FESS) on facial pain}

The way FESS influences headache has been under investigation for a lengthy period, and such research may help to provide information on the putative links between sinonasal inflammation and facial pain. Lal ${ }^{12}$ stated that 66 of 211 patients (31.28\%) undergoing endoscopic sinus surgery experienced pain relief. However, the population studied consisted of a mixture of cases referred from both ENT and neurology departments for sinus pressure or pain. The obstruction relinquished most often where the patient had received neurological input, either previously or concurrently. Indeed, $36 \%$ of cases, which had failed to improve on surgical intervention, were then given a primary diagnosis of headache disorder when reviewed by a neurologist. From research with more stringent inclusion criteria (including only genuine sinusitis and facial pain), the FESS success rate increases to 75-91.9\% 49203536 . A study with a follow-up period of 7 to 8 years noted that $47 \%$ of the 51 cases included remained without headache throughout follow-up ${ }^{37}$.

Some studies have looked at cases where FESS was carried out despite no endoscopic or CT confirmation of sinus pathology or anatomical anomaly. Boonchoo ${ }^{38}$ carried out FESS in 16 cases where headache existed, but CT findings demonstrated no anomaly. Ten of these ended up completely pain-free, while the remaining 6 had some degree of alleviation. In a similar vein, Cook et al. ${ }^{39}$ observed that 12 of 18 cases undergoing the procedure found it of benefit, although none saw their symptoms disappear completely.

If an individual experiences abrupt changes in pressure, for example while diving, flying, or skiing, regardless of whether they suffer from rhinosinusitis or not, they may have short lived facial pain, which, however, abates within hours thanks to increasing vascular perfusion over time. Such individuals frequently find surgical interventions that increase ostial patency to be of benefit ${ }^{23}$. By contrast, longer lasting ostial blockage is rarely the cause of uninterrupted facial pain. Silent sinus syndrome exemplifies this fact, in which an occluded sinus resorbs its contents, and the maxillary sinus is weakened to the extent that the orbit may prolapse into it. Despite this, the condition is painless. A similar effect may be responsible when intraoperative damage to afferents leading to the trigeminal nucleus causes the threshold for spontaneous discharge to be reset briefly ${ }^{32}$. 
Other rhinologic disorders occasioning sinogenic facial pain Sinus mucocoeles, which expand gradually in a cystic fashion are among other diseases treated by a rhinologist that may cause facial pain. When the mucocele attains sufficient magnitude to impinge on the osteous wall of the sinus, pain results. A mucocoele of the maxillary sinus may occlude the ostiomeatus, resulting in sinusitis. The most significant lesion from a clinical viewpoint is a fronto-ethmoidal mucocoele, since it provokes frontal headaches and pain in the orbit. Pain over the occiput, the vertex, or deep nasal region may be the result of a spheno-ethmoidal mucocoele ${ }^{4041}$.

Where pain does not vary and has been worsening, other worrying features or neural signs are present, a neoplasm should be suspected, even if facial pain is seldom a presenting feature. A pus-filled, sanguineous discharge occurring on one side of the nose and blockage of the nose are more usual. Pain usually occurs at an advanced stage. Para-aesthetic sensation below the orbit, loosened denti- tion, dentures that no longer fit, proptosis, malar deformity and watering eyes are possible, less common signs. Radiological imaging is essential.

\section{"Non-sinogenic" facial pain}

The worldwide prevalence of some form of headache is $46 \%$. Amongst non-sinogenic causes there are primary headache syndromes such as migraine and related disorders, tension headache and trigeminal autonomic cephalalgias (TACs). Somewhat seldom are headaches secondary to another condition, e.g. infection, vascular pathology, substance misuse, psychiatric illness and lesions or injuries of the cranial nerves, according to ICHD-III. The latter are often included in potential causes when assessing cases of facial pain thought to be sinogenic.

Diagnostic criteria for the most frequent types of primary headache are listed in Table II.

Table II. Diagnostic criteria for most frequent primary headaches. Headache Classification Committee of the International Headache Society (IHS) ${ }^{1}$.

\begin{tabular}{|c|c|c|c|}
\hline Migraine without aura & Migraine with aura & $\begin{array}{l}\text { Frequent episodic tension } \\
\text { type }\end{array}$ & Cluster headache \\
\hline $\begin{array}{l}\text { A. At least } 5 \text { attacks fulfilling } \\
\text { criteria B-D }\end{array}$ & A. At least 2 attacks fulfilling criteria B-C & $\begin{array}{l}\text { A. At least } 10 \text { episodes } \\
\text { occurring on } 1 \text { to } 14 \mathrm{~d} / \mathrm{mo} \text { on } \\
\text { average for }>3 \mathrm{mos}(>12 \\
\text { and }<180 \mathrm{~d} / \mathrm{y}) \text { and fulfilling } \\
\text { criteria } \mathrm{B}-\mathrm{D}\end{array}$ & $\begin{array}{l}\text { A. At least } 5 \text { attacks fulfilling criteria } \\
\text { B-D }\end{array}$ \\
\hline $\begin{array}{l}\text { B. Headache attacks } \\
\text { lasting } 4-72 \mathrm{~h} \text { (untreated or } \\
\text { unsuccessfully treated) }\end{array}$ & $\begin{array}{l}\text { B. } 1 \text { or more of the following fully } \\
\text { reversible aura symptoms: } \\
\text { 1. visual; } \\
\text { 2. sensory; } \\
\text { 3. speech and/or language; } \\
\text { 4. motor; } \\
\text { 5. brainstem; } \\
\text { 6. retinal. }\end{array}$ & B. Headache lasting 30 min-7 d & $\begin{array}{l}\text { B. Severe or very severe unilateral } \\
\text { orbital, supraorbital, and/or temporal } \\
\text { pain lasting 15-180 min (when } \\
\text { untreated) }\end{array}$ \\
\hline $\begin{array}{l}\text { C. Headache has at least } 2 \text { of the } \\
\text { following characteristics: } \\
\text { 1. unilateral location; } \\
\text { 2. pulsating quality; } \\
\text { 3. moderate or severe pain } \\
\text { intensity; } \\
\text { 4. aggravation by/or causing } \\
\text { avoidance of routine physical } \\
\text { activity (e.g. walking or } \\
\text { climbing stairs). }\end{array}$ & $\begin{array}{l}\text { C. Headache has at least } 3 \text { of the } \\
\text { following characteristics: } \\
\text { 1. at least } 1 \text { aura symptom spreads } \\
\text { gradually over } \geq 5 \text { min; } \\
\text { 2. two or more aura symptoms occur in } \\
\text { succession; } \\
\text { 3. each individual aura symptom } \\
\text { lasts } \geq 5 \text { and } \leq 60 \text { min; } \\
\text { 4. at least } 1 \text { aura symptom is unilateral; } \\
\text { 5. at least } 1 \text { aura symptom is positive; } \\
\text { 6. the aura is accompanied, or followed } \\
\text { within } 60 \text { min, by headache. }\end{array}$ & $\begin{array}{l}\text { C. Headache has at } \\
\text { least } 2 \text { of the following } \\
\text { characteristics: } \\
\text { 1. bilateral location; } \\
\text { 2. pressing/tightening } \\
\text { (nonpulsating) quality; } \\
\text { 3. mild or moderate intensity } \\
\text { of pain; } \\
\text { 4. not aggravated by routine } \\
\text { physical activity (e.g., } \\
\text { walking or } \\
\text { climbing stairs). }\end{array}$ & $\begin{array}{l}\text { C. Either or both of the following: } \\
\text { 1. at least one of the following } \\
\text { symptoms or signs, ipsilateral to } \\
\text { headache: } \\
\text { a. conjunctival injection and/or } \\
\text { lacrimation; } \\
\text { b. nasal congestion and/or } \\
\text { rhinorrhea; } \\
\text { c. eyelid oedema; } \\
\text { d. forehead and facial sweating; } \\
\text { e. miosis and/or ptosis. } \\
\text { 2. sense of restlessness or agitation }\end{array}$ \\
\hline $\begin{array}{l}\text { D. During headache, at least } 1 \text { of } \\
\text { the following: } \\
\text { 1. nausea and/or vomiting; } \\
\text { 2. photophobia and }\end{array}$ & $\begin{array}{l}\text { D. Not better accounted for/by another } \\
\text { ICHD-III diagnosis }\end{array}$ & $\begin{array}{l}\text { D. Both of the following: } \\
\text { 1. no nausea or vomiting; } \\
\text { 2. no more than } 1 \text { of } \\
\text { photophobia or phonophobia. }\end{array}$ & $\begin{array}{l}\text { D. Occurring with frequency between } 1 \\
\text { every other day and } 8 \text { per day }\end{array}$ \\
\hline
\end{tabular}




\section{Primary headaches}

\section{Migraine}

Migraines are frequently seen as a common cause of infirmity, they contribute significantly to absence from work, reduce employee productivity and cause reduced quality of life that can be readily shown ${ }^{42}$. Worldwide, $11 \%$ of adults are sufferers ${ }^{43}$, with a female to male ratio of $3: 1$, with the bias being attributed to hormonal changes. Children and elderly people are less commonly affected. The daily incidence in the general population is 3,000 in $1,000,000^{44}$.

The symptomatology of migraine shares common features with other headache types: tension, cluster and "sinus". The IHS defines migraine as of 4-72 hours duration when untreated coupled with particular features, i.e. pulsating pain on one side (40\% are two-sided, however), affecting the face plus head. In a small number of cases pain is localised to the orbit alone and even more unusually, just the cheek and nose; there is often a prodrome, with 20$30 \%$ of sufferers describing an aura that may often affect vision. There are two principal variants: migraine minus aura (which used to be referred to as common migraine and affects around $75 \%$ of sufferers) and migraine plus aura (also known as classic migraine, affecting around $25 \%$ ). Females have 3 times the likelihood of the condition and family history is common ${ }^{45}$.

The onset of an aura is 5-20 minutes and typically finishes within an hour. Headaches then typically commence less than 60 minutes after the aura has stopped, albeit on occasion the headache may not begin for several hours, and there may be sporadic absence of pain. $64 \%$ of attacks have no preceding migraine and this is the most usual type ${ }^{46}$.

Migraines trigger action from the trigemino-vascular afferent nerves, leading to greater vascular perfusion of the dura mater ${ }^{47}$. The pain may occur in tandem with photophobia, acoustic hyperresponsivity and gut symptoms, e.g. nausea and vomiting.

\section{Tension-type headaches (TTHs)}

More than $70 \%$ of some populations describe having headaches of episodic tension-type, making it the most common of all headaches. However, the exact annual prevalence seemingly differs, being, on average, $42 \%$ amongst adults, with females more commonly affected than males. The chronic form has a prevalence of $1-3 \%{ }^{43}$. TTH occurs bilaterally, tends to recur, has a duration of between minutes and weeks and is accompanied by a feeling of pressure or constriction that ranges from mildly to moderately severe. Usually none of the features that characterise migraine, such as nausea and vomiting, are present. However, excessive sensitivity to sounds or light may occur ${ }^{48}$. Frequently, no identifiable worsening or relieving factors are identified, even if sufferers may notice that bending forward worsens the situation, which may then lead to incorrectly ascribing the symptoms to pathology of the sinuses. The soft tissues may become sensitive to touch in TTH and may extend over the whole skull, with muscles being acutely tender and certain points, when touched, producing the sensation of pain. Notably, pressing for a long time on one point may result in pain referred elsewhere.

To diagnose TTH, the clinician must take a meticulous history, since the diagnosis hinges on identifying how long pain lasts, what type it is and how marked, alongside demonstrating clearly that concurrent symptomatology e.g. nausea and vomiting is absent. Asking what sets off or worsens an attack is valuable since TTH is both precipitated and aggravated by psychological pressure, lack of sleep and eating inadequately. It also helps when counselling patients about changing their lifestyle to cut down on the number of headaches and their severity when they do occur ${ }^{49}$.

\section{Trigeminal autonomic cephalalgias (TACs)}

\section{a) Cluster headache}

Cluster headache is rather rare, but severe. It is a primary headache and typically consists of one-sided headaches that recur and classically interrupt sleep. Generally, the same side is affected each time and the pain is exceptionally severe at certain times. The episodes last from $15 \mathrm{~min}$ to 3 hours and affect the area behind the orbit or the midorbit. There is an accompanying autonomic neuropathy on the same side leading to nasal discharge, tearing and inability to sweat (due to parasympathetic activity), coupled with tiny pupils and ptosis (resulting from sympathetic outflow). It is periodic (which may reflect a circadian rhythm) and the attacks are present for 8 to 10 weeks a year, although there should be an entirely asymptomatic interlude of no less than a fortnight between attacks. Around 15 to $20 \%$ of sufferers with cluster headaches of a chronic type do not have asymptomatic interludes. They do not experience prodromal symptoms nor aura ${ }^{50}$. Alcoholic drinks such as red wine or nitroglycerin may set off an episode during times when patients are symptomatic, or for those with a chronic form of the disorder. The classical presentation is in a male aged 20 to 40 . Males are, in fact, six times more likely to have the disorder than females ${ }^{51}$.

b) Paroxysmal hemicrania

Paroxysmal hemicrania causes extreme one-sided pain, 
generally around the eyes and the forehead, which lasts between 2 and 45 minutes. While the usual presentation is unilateral, bilateral attacks also occur. The mean age at first episode is within the fourth decade of life, but the age range affected encompasses 6 to 81. The episodic variant affects younger patients and typically causes attacks to happen frequently, generally 5 times daily. Remission may be between three months and three years. At least one feature of autonomic dysfunction must be observed: blocked nose, nasal discharge, tearing, bloodshot eyes, ptosis, swollen eyelid, altered cardiac rhythm (brady- or tachy-cardic, extrasystole), localised epiphora, saliva production and flushing of the face ${ }^{52}$.

c) Hemicrania continua

This condition shares the feature with chronic paroxysmal hemicrania of being a one-sided headache that shows definite responsivity to indomethacin. Its severity is moderate, does not switch sides and the pain is unswerving, albeit allowing for variations in intensity and peak intensity brought about by autonomic dysfunction (bloodshot eyes, tearing and avoiding bright light on the side involved) ${ }^{53}$.

d) Short-lasting unilateral neuralgiform headache attacks with conjunctival injection and tearing (SUNCT) syndrome SUNCT comprises a syndrome of headaches of unknown aetiology, which is distinguished by pain over the trigeminal distribution, especially around and within the orbit, and has associated autonomic features (bloodshot eyes and lacrimation). The duration of attacks is 15 seconds to 1 minute and happens anywhere between 5 and 30 times each hour. The action of chewing and eating sour-tasting foods can trigger episodes ${ }^{54}$.

\section{Secondary headaches, involving cranial nerves}

\section{Trigeminal neuralgia}

The abrupt onset of sharp, stab-like pains that endure from a matter of seconds to under 2 minutes and recur several times during a brief interval, where such pains are brought on by a sensory or mechanical stimulus, supports a diagnosis of cranial neuralgia. The majority of facial neuralgias follow a similar pattern ${ }^{55}$. By far the most common of these is trigeminal neuralgia. It is well known that extreme stabbing pains occur in waves following stimulation of a particular trigger point. While both maxillary and mandibular branches are affected in many cases (CNV2 and CNV3), one in five trigeminal neuralgias involves only the maxillary branch. Only $4 \%$ of trigeminal neuralgias are confined to the ophthalmic branch (CNV1) ${ }^{56}$.

Trigeminal neuralgia may occur without any trigger or may come about through sensation originating in specific facial regions (cheek, chin, lips or tongue). Such origins generally correspond to where the pain is. The usual triggers are touch to the face, washing, shaving, cleaning teeth, or mastication. Facial flushing may be observed. During its natural history, the frequency of painful attacks increases, and the asymptomatic intervals shorten. While it is frequent for the disease to remit, it may also worsen. If the sufferer is young, MRI evaluation is necessary to exclude other conditions such as widespread sclerosis or neoplasms (e.g. meningioma or neuroma) of the posterior fossa.

\section{Other nerve-related conditions}

Glossopharyngeal neuralgia is a seldom-encountered condition in which pain occurs in sudden flare-ups, and affects the pharynx, lingual base, velum and tonsillar fossae, potentially extending to the lower jaw angle or, unusually, the external acoustic meatus ${ }^{57}$. Frequently, deglutition, mastication, speech, laughter or coughing. Occipital neuralgia, nervus intermedius (geniculate) and supraorbital neuralgia are much less frequently seen conditions. Charlin's neuralgia and Sluder's neuralgia generally affect the medial ocular angle. In most cases, the pain goes towards the superciliary, orbital or nasal and mandibular regions. Tearing, bloodshot eyes, blocked nose, sternutation and frontal erythema are characteristic signs/symptoms ${ }^{58} 59$. This pattern is, therefore, hard to disentangle from the separate cluster headache phenomenon.

\section{Persistent idiopathic facial pain}

The other term for this condition, atypical facial pain, is preferred by the IHS. The pain is unremitting, deeply felt and frequently only affects one side. Patients frequently give an unclear and changeable account of their symptoms, describing pain that affects multiple areas including the face and other regions of the head and neck. Many times, they have already had sinus operations or dental treatment and may be displeased about the outcome. A somewhat frequent situation is a history of traumatic injury to the nose. Numerous sufferers from atypical facial pain have noticeable psychological difficulties or have had depression and the pain interferes with their normal functioning. Most often the patient is a female aged above 40 years. Detailed physical assessment, encompassing nasal endoscopy, is mandatory, and an MRI would be a worthwhile precaution before settling on atypical pain as a final diagnosis.

\section{Differential diagnosis}

The history must include information on what the patient recalls about previous pain episodes if the diagnosis is to 
accurately reflect an origin in the sinuses or not. More specifically, there must be recollection of: time course (when it started, how long it lasts and how frequently it occurs); site and where it spreads to (e.g. does it follow the distribution of a nerve?); type of pain and how marked; how it responds to pharmacological intervention; what helps and what makes it worse (such as eating hot, cold or sweet items, chewing a long time, swallowing, cleaning teeth, facial touch, weather conditions, doing particular things, posture, being stressed or tired); other factors (effect on taste, amount of saliva, clenching or grinding teeth, TMJ problems, changed sensation, symptoms affecting the nose, eyes or ears); effect on sleep, mood, ability to focus, tiredness level, associated thoughts and general life quality.

Just as with other chronic pain syndromes, mental status, family and social history and important life happenings all merit consideration. Physical examination may reveal different colouration, oedema and cutaneous lesions. Cranial nerves should be assessed. Since pain is a subjective phenomenon, the use of special questionnaires may help. The Brief Pain Inventory, Beck Depression Inventory, Hospital Anxiety and Depression Scale and McGill Pain Questionnaire have adequate sensitivity and validation ${ }^{6061}$. Other than when assessing cranial arteritis or auto-immune pathologies, such as Sjögren's syndrome, in vitro and pathological tests are of no help ${ }^{62}$.

The AAO-HNS advises that rhinosinusitis diagnosis depends critically on the use of nasal endoscopy and radiology. For instance, there are reports of disease mimicry occurring due to other conditions ${ }^{63}$. Hyperaemic mucosae and pus-containing secretions are frequent findings at endoscopy. In situations where the patient has no symptoms and endoscopy reveals no abnormality, a repeated endos- copy during a symptomatic period is of value. Nevertheless, it is worth bearing in mind that migraine attacks have also been shown to be associated with oedema of the lining of the nose ${ }^{11}$. Endoscopy can also beneficially identify sites of mucosal impingement, although the existence of such contact points does not invariably correlate with an origin for pain in the sinuses ${ }^{23}$, even where inflammation and infection are present.

Plain X-ray views of the sinuses may support a diagnosis of acute bacterial rhinosinusitis, but for chronic rhinosinusitis, they lack both sensitivity and specificity. For certain disorders, CT or MRI are indicated, but CT may give a misleading impression about the sinuses since approximately $30 \%$ of normal subjects have the appearance of thickened mucosae and the area of increased opacification on CT has no relation to where pain is actually felt. Hence, increased opacification need not mean the pain is sinogenic ${ }^{61}$. Evaluating CT scans using different methods of scoring (Harvard and Kennedy) failed to improve the correlation ${ }^{64}$ and, indeed, only a weak association existed between $\mathrm{CT}$ appearances as scored using Lund-Mackay and the degree of chronic rhinosinusitis ${ }^{65}$. Mehle studied a group of individuals who referred themselves for a "sinus headache" and discovered that scores using LundMackay criteria are not significantly different for the presence or absence of migraine.

Differences apparent clinically between sinus and nonsinus origin headache are outlined in Table III.

\section{Conclusions}

Individuals suffering from chronic facial pain experience significant changes in their lives and functioning. Identi-

Table III. Differences between sinogenic and non-sinogenic pain in term of clinical features.

\begin{tabular}{lll} 
Features & Sinogenic pain & Non-sinogenic pain \\
$\begin{array}{l}\text { Severity of pain } \\
\text { Quality of pain }\end{array}$ & Mild/moderate & Moderate/severe \\
$\begin{array}{l}\text { Duration } \\
\text { Location }\end{array}$ & Pressure/congestion & Pulsatile/tightening/excruciating \\
& $>72$ hours & hours \\
Triggers & Frequently unilateral and depending on the sinus of origin & $\begin{array}{l}\text { Unilateral/bilateral. Poor correlation between the site of facial } \\
\text { pain and sinuses anatomy }\end{array}$ \\
$\begin{array}{l}\text { Frequently associated } \\
\text { features }\end{array}$ & Variations in atmospheric pressure (e.g. flying, skiing, diving) & Exercises, menstrual cycle, certain foods (e.g. chocolate, cheese) \\
ENT examination & Nasal congestion, mucosal oedema and purulent nasal discharge & No abnormalities or nasal mucosal congestion \\
Nasal endoscopy & Purulent nasal discharge (anterior/ posterior), mucosal oedema, & No abnormalities or nasal mucosal congestion \\
& $+/-$ polyps, occlusion of osteomeatal complex and/or spheno- & \\
& etmhmoidal recess & \\
CT scan & Sinuses opacification; osteomeatal complex and/or spheno- & No abnormalities \\
& etmhmoidal recess occlusion & \\
\hline
\end{tabular}




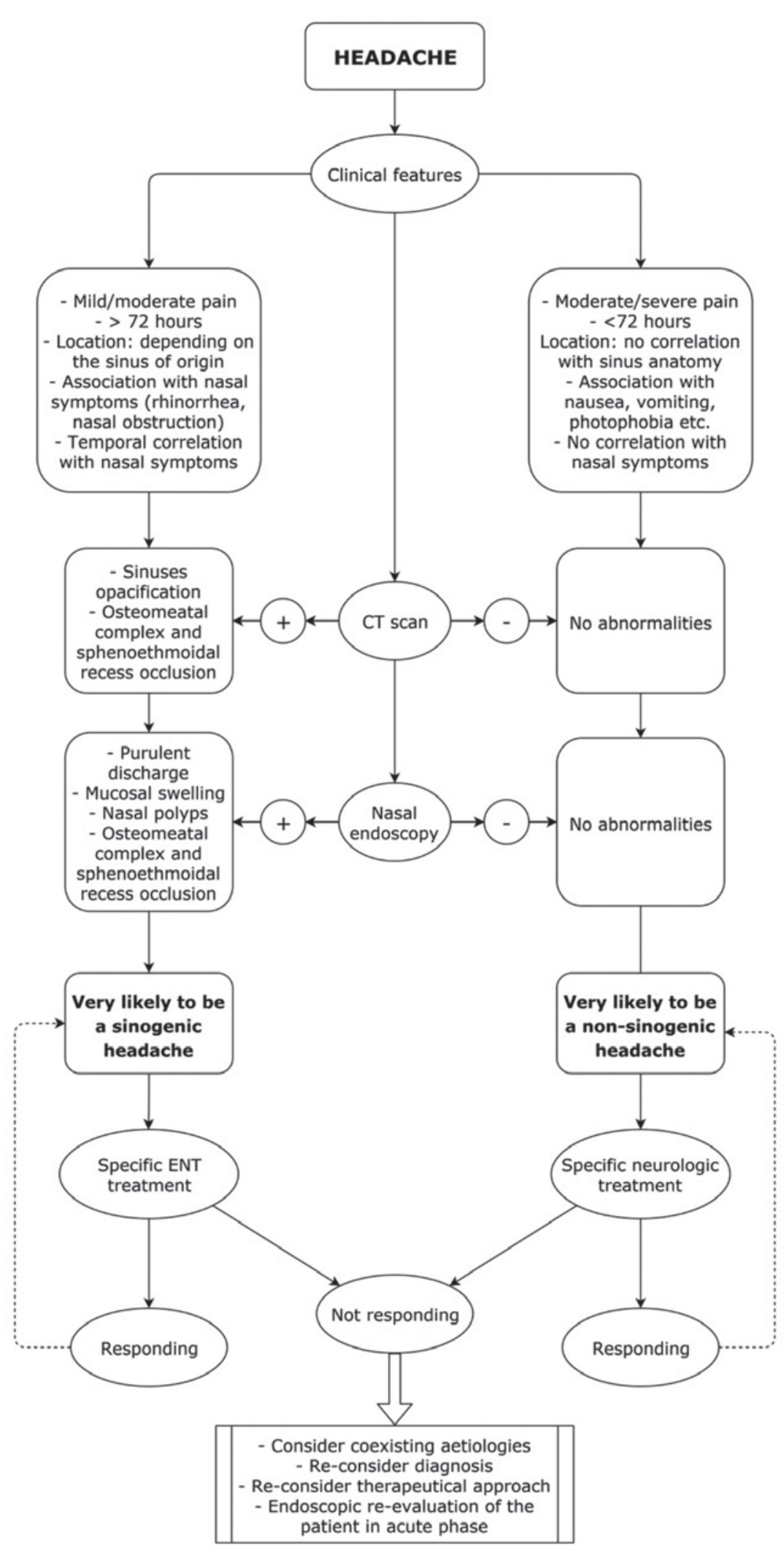

Fig. 1. Specific algorithm for thoroughly investigating the aetiology of facial pain. 
fying the likely cause and treating appropriately may represent a clinical challenge and currently much remains to be discovered about the underlying pathology. Significant attempts have been made to separate different disorders on the basis of clinical features. The most usual way of classifying individuals is in terms of the underlying pathology. For a number of conditions, e.g. trigeminal neuralgia or cluster headache, clinical definitions are well established, despite the lack of confirmatory diagnostic investigations. One method of confirming the clinical impression is by observing the response to treatment. The current classification scheme suffers, however, from being inadequate for numerous cases that do not easily fit in one category, and for having a significant degree of overlap between syndromes.

The aim of this study is to highlight the optimal ways in ENT to diagnose facial pain arising from the sinuses. The published research indicates that nasal endoscopy is more specific than CT in the diagnosis of rhinosinusitis. Where nasal endoscopy is negative, the likelihood that pain in the face is sinogenic is very low. Pain originating in the sinuses is not likely to occur where the interior of the nose has neither pus-filled secretion nor swollen mucosae, and this is especially so where there is pain at the time of examination or in the recent past. A normal endoscopy on a symptom-free day may, however, need to be repeated during an episode of pain.

Facial pain or pressure, if unaccompanied by other clinical features pointing to nasal involvement, is rarely the result of sinus pathology. In any case, it is noteworthy that blockage of the nose with or without a clear nasal discharge may co-occur with facial pain elicited by vascular problems. Such a situation is, nonetheless, typically of short duration, seldom exceeding 72 hours.

For individuals experiencing unremitting pain of identical distribution bilaterally, midfacial segment pain is a diagnosis of exclusion. Where patients come with a history of recurrent acute rhinosinusitis but are asymptomatic at interview, they should return when symptoms recur. Given the rarity of bacterial rhinosinusitis, a vascular origin for their pain is a distinct possibility.

In this article, we have compared the differing features of sinogenic and non-sinogenic pain in a comprehensive way. Inappropriately classifying the reason for facial pain may explain treatment failures. Inappropriate diagnosis and consequent treatment appear to be common, from the epidemiological data we have gathered. Individuals having facial pain, but no corroborating sinus pathology at endoscopy, have a minimal chance of rhinosinusitis and thus are unlikely to benefit from operations or pharmacological interventions intended for sinus disease. Managing those with sinus pressure or fullness, facial pain, or headache can represent a clinical challenge, and this is best addressed using an approach that identifies the aetiology, whether rhinosinusitis, neurogenic or some other pathology. ENT practitioners are well-placed to assist in most cases of facial pain since their specialty is able to pinpoint the underlying aetiology, whether sinogenic or not. Figure 1 summarises our suggested clinical algorithm, which can help clinicians identify the underlying cause.

\section{Conflict of interest statement}

None declared.

\section{References}

1 Headache Classification Committee of the International Headache Society (IHS). The International Classification of Headache Disorders. $3^{\text {rd }}$ edition. Cephalalgia 2018;38:1-211.

2 Mertens E. Modifying factors on perception and expression of pain. Pflege Z 2007;60:312.

3 Lerman SF, Rudich Z, Brill S. Longitudinal associations between depression, anxiety, pain, and pain-related disability in chronic pain patients. Psychosom Med 2014;77:333-41.

4 West B, Jones NS. Endoscopy-negative, computed tomography negative facial pain in a nasal clinic. Laryngoscope 2001;111:581-6.

5 Fahy C, Jones NS. Nasal polyposis and facial pain. Clin Otolaryngol 2001;26:510-3.

6 Gelardi M, Iannuzzi L, De Giosa M, et al. Non-surgical management of chronic rhinosinusitis with nasal polyps based on clinical-cytological grading: a precision medicine-based approach. Acta Otorhinolaryngol Ital 2017;37:38-45.

7 Walliczek-Dworschak U, Diogo I, Strack L, et al. Indication of cone beam CT in head and neck imaging in children. Acta Otorhinolaryngol Ital 2017;37:270-5.

8 Tarabichi M. Characteristics of sinus-related pain. Otolaryngol Head Neck Surg 2000;122:84-7.

9 Jones NS, Cooney TR. Facial pain and sinonasal surgery. Rhinology 2003;41:193-200.

10 Graff-Radford SB. Facial pain. Curr Opin Neurol 2000;13:291-6.

11 Cady RK, Schreiber CP. Sinus headache: a clinical conundrum. Otolaryngol Clin North Am 2004;37:267-88.

12 Lal D, Rounds A, Dodick DW. Comprehensive management of patients presenting to the otolaryngologist for sinus pressure, pain, or headache. Laryngoscope 2015;125:303-10.

13 Barbanti P, Fabbrini G, Pesare M, et al. Unilateral cranial autonomic symptoms in migraine. Cephalalgia 2002;22:256-9.

14 Schreiber CP, Hutchinson S, Webster CJ, et al. Prevalence of migraine in patients with a history of self-reported or physician-diagnosed "sinus" headache. Arch Intern Med 2004;164:1769-72. 
15 Eross E, Dodick D, Eross M. The Sinus, Allergy and Migraine Study (SAMS). Headache 2007;47:213-24.

16 Mehle ME, Kremer PS. Sinus CT scan findings in "sinus headache" migraineurs. Headache 2008;48:67-71.

17 Perry BF, Login IS, KSE. Nonrhinologic headache in a tertiary rhinology practice. Otolaryngol Head Neck Surg 2004;130:449-52.

18 Lipton RB, Manack Adams A, Buse DC, et al. Migraine diagnosis and treatment: results from the American Migraine Study II. Headache 2001;41:1280-9.

19 Lee JH. Underestimation of rhinogenic causes in patients presenting to the emergency department with acute headache. Acta Neurol Taiwan 2015;24:37-42.

20 Aaseth K, Grande RB, Kvaerner K, et al. Chronic rhinosinusitis gives a ninefold increased risk of chronic headache. The Akershus study of chronic headache. Cephalalgia 2010;30:152-60.

21 Farri A, Enrico A, Farri F. Headaches of otolaryngological interest: current status while awaiting revision of classification. Practical considerations and expectations. Acta Otorhinolaryngol Ital 2012;32:77-86.

22 Berg O, Carenfelt C. Analysis of symptoms and clinical signs in the maxillary sinus empyema. Acta Otolaryngol 1988;105:343-9.

23 Fokkens WJ, Lund VJ, Mullol J, et al. EPOS 2012: European position paper on rhinosinusitis and nasal polyps 2012. A summary for otorhinolaryngologists. Rhinology 2012;50:1-12.

24 Clifton NJ, Jones NS. Prevalence of facial pain in 108 consecutive patients with paranasal mucopurulent discharge at endoscopy. J Laryngol Otol 2007;121:345-8.

25 Hirsch AG, Stewart WF, Sundaresan AS, et al. Nasal and sinus symptoms and chronic rhinosinusitis in a populationbased sample. Allergy 2017;72:274-81.

26 Gamerra M, Cantone E, Sorrentino G, et al. Mathematical model for preoperative identification of obstructed nasal subsites. Acta Otorhinolaryngol Ital 2017;37:410-5.

27 Gelardi M, De Candia N, Quaranta N, et al. The relevance of counseling in patients with nasal polyps. Acta Otorhinolaryngol Ital 2016;36:326-7.

28 Morgenstein KM, Krieger MK. Experiences in middle turbinectomy. Laryngoscope 1980;90:1596-603.

29 Anselmo-Lima WT, de Oliveira JA. Middle turbinate headache syndrome. Headache 1997;37:102-6.

30 Greenfield DP. Diagnosis and clinical management of headaches. CNS Spectr 1999;4:32-47.

31 Cantone E, Castagna G, Ferranti I, et al. Concha bullosa related headache disability. Eur Rev Med Pharmacol Sci 2015;19:2327-30.

32 Stammberger $\mathrm{H}$, Wolf $\mathrm{G}$. Headaches and sinus disease: the endoscopic approach. Ann Otol Rhinol Laryngol 1988;134:3-23.

33 Harrison L, Jones NS. Intranasal contact points as a cause of facial pain or headache: a systematic review. Clin Otolaryngol 2013;38:8-22.
34 Abu-Bakra M, Jones NS. Prevalence of nasal mucosal contact points in patients with facial pain compared with patients without facial pain. J Laryngol Otol 2001;115:629-32.

35 Falco JJ, Thomas AJ, Quin X, et al. Lack of correlation between patient reported location and severity of facial pain and radiographic burden of disease in chronic rhinosinusitis. Int Forum Allergy Rhinol 2016;6:1173-81.

36 Moretz WH, Kountakis SE. Subjective headache before and after endoscopic sinus surgery. Am J Rhinol 2006;20:305-7.

37 Senior BA, Kennedy DW, Tanabodee J, et al. Long-term results of functional endoscopic sinus surgery. Laryngoscope 1998;108:151-7.

38 Boonchoo R. Functional endoscopic sinus surgery in patients with sinugenic headache. J Med Assoc Thai 1997;80:521-6.

39 Cook PR, Nishioka GJ, Davis WE, et al. Functional endoscopic sinus surgery in patients with normal computed tomography scans. Otolaryngol Head Neck Surg 1994;110:505-9.

40 Cummings CW. Otolaryngology: head and neck surgery. $4^{\text {th }}$ edition. Mosby; 2005.

41 Yüce S, Akal A, Doğan M, et al. Results of endoscopic endonasal dacryocystorhinostomy. J Craniofac Surg 2013;24:e11-2.

42 Lanteri-Minet M. Economic burden and costs of chronic migraine. Curr Pain Headache Rep 2014;18:385.

43 Stovner LJ, Hagen K, Jensen R, et al. The global burden of headache: a documentation of headache prevalence and disability worldwide. Cephalalgia 2007;27:197-210.

44 Steiner TJ, Scher AI, Stewart WF, et al. The prevalence and disability burden of adult migraine in England and their relationships to age, gender and ethnicity. Cephalalgia 2003;23:519-27.

45 Kelman L. The premonitory symptoms (prodrome): a tertiary care study of 893 migraineurs. Headache 2004;44:865-72.

46 Truong T, Slavin L, Kashani R, et al. Prevalence of migraine headaches in patients with congenital heart disease. Am J Cardiol 2008;101:396-400.

47 Pietrobon D, Moskowitz MA. Pathophysiology of migraine. Annu Rev Physiol 2013;75:365-91.

48 Sahler K. Epidemiology and cultural differences in tensiontype headache. Curr Pain Headache Rep 2012;16:525-32.

49 Freitag F. Managing and treating tension-type headache. Med Clin North Am 2013;97:281-92.

50 Bernstein JA, Fox RW, Martin VT, et al. Headache and facial pain: differential diagnosis and treatment. J Allergy Clin Immunol Pract 2013;1:242-51.

51 Lanteri-Minet M. Epidemiology, clinical presentation, diagnosis, natural history and screening of cluster headache. Presse Med 2015;44:1176-9.

52 Prakash S, Patell R. Paroxysmal hemicrania: an update. Curr Pain Headache Rep 2014;18:407.

53 Viana M, Tassorelli C, Allena M, et al. Diagnostic and therapeutic errors in trigeminal autonomic cephalalgias and hemicrania continua: a systematic review. J Headache Pain 2013;14:14. 
54 Pomeroy JL, Nahas SJ. SUNCT/SUNA: a review. Curr Pain Headache Rep 2015;19:38.

55 Cheshire WPJ. Cranial neuralgias. Continuum (Minneap Minn) 2015;21:1072-85.

56 Maarbjerg S, Gozalov A, Olesen J, et al. Trigeminal neuralgia: a prospective systematic study of clinical characteristics in 158 patients. Headache 2014;54:1574-82.

57 Reddy GD, Viswanathan A. Trigeminal and glossopharyngeal neuralgia. Neurol Clin 2014;32:539-52.

58 Oomen KP, Van Wijck AJ, Hordijk GJ, et al. Sluder's neuralgia: a trigeminal autonomic cephalalgia. Cephalalgia 2010;30:360-4.

59 Vinken PJ, Bruyn GW. Charlin's neuralgia. In: Rose FC, editor. Headache: handbook of clinical neurology. Amsterdam: Elsevier; 1986. p. 483-86.

60 DeConde AS, Mace JC, Ashby S, et al. Characterization of facial pain associated with chronic rhinosinusitis using validated pain evaluation instruments. Int Forum Allergy Rhinol 2015;5:682-90.
61 Smarr KL, Keefer AL. Measures of depression and depressive symptoms: Beck Depression Inventory-II (BDI-II), Center for Epidemiologic Studies Depression Scale (CES-D), Geriatric Depression Scale (GDS), Hospital Anxiety and Depression Scale (HADS) and Patient Health Questionnaire-9 (PHQ-9).Arthritis Care Res 2011;63:S454-66.

62 Jones NS. Sinogenic facial pain: diagnosis and management. Otolaryngol Clin North Am 2005;38:1311-25.

63 Batra PS, Setzen M, Li Y, et al. Computed tomography imaging practice patterns in adult chronic rhinosinusitis: survey of the American Academy of Otolaryngology Head and Neck Surgery and American Rhinologic Society membership. Int Forum Allergy Rhinol 2015;5:506-12.

64 Shields G, Seikaly H, LeBoeuf M, et al. Correlation between facial pain or headache and computed tomography in rhinosinusitis in Canadian and U.S. subjects. Laryngoscope 2003;113:943-5.

65 Hopkins C, Browne JP, Slack R, et al. The Lund-Mackay staging system for chronic rhinosinusitis: how is it used and what does it predict? Otolaryngol Head Neck Surg 2007;137:555-61.

Received: April 19, 2017 - Accepted: May 29, 2018

Address for correspondence: Nuray Bayar Muluk, Birlik Mahallesi, Zirvekent 2, Etap Sitesi, C-3 blok, 6-3/4306610 Çankaya/Ankara, Turkey. Tel. +90 535 6655718; +90 532 7182441. Fax +90 312 4964073. E-mail: nbayarmuluk@yahoo.com 